\title{
(CIBER)LEITORAS/ES EM THE.POWERBOOK DE JEANETTE WINTERSON
}

\section{Ana Cecília Acioli Lima*}

Resumo: Neste ensaio pretendo discutir as formas em que Jeanette Winterson em The.PowerBook (2000) desestabiliza as relações entre autor/a e leitor/a, assim como as relações entre corpos e identidades, através de narrativas que circulam no ciberespaço, e que diluem e confundem as figuras do/a autor/a e do/a leitor/a em uma infinidade de pontos de vista que se deslocam e se transformam no tempo e no espaço. No campo da textualidade eletrônica, que o livro simula, (ciber)autor/a e (ciber)leitor/a relacionam-se apenas enquanto identidades fluidas e provisórias, no universo da complexa tecnologia hipertextual.

Palavras-chave: Ficção pós-moderna; Hipertexto; Corpo; Ciberleitor/a

\section{A PÓS-MODERNIDADE E A QUESTÃO DA AUTORIA}

Será que nos chamados tempos pós-modernos em que vivemos podemos falar em autor/a? Será que de fato existe uma subjetividade real por trás de um texto, que lhe possa garantir alguma coerência estrutural e/ou de significados? Essas questões, inevitavelmente, nos levam a repensar da mesma forma o papel do/a leitor/a - é possível falarmos em um/a leitor/a independente, capaz de estabelecer uma relação dialógica única e coerente com o texto literário?

A analogia entre autor/a e Deus é um tema ontológico clássico na teoria e na filosofia da literatura. O poeta inglês, Sir Philip Sidney, em sua "The Defence of Poesy",' de 1595, defendia uma idéia que, na verdade, era lugar-comum na Renascença - a de que o poeta, o sujeito que conhece, o demiurgo - com uma função quase divina - cria um mundo outro, "uma outra natureza". Assim, Sidney situava o mundo ficcional como um heterocosmo, um universo similar, e, por isso mesmo, diferente do real. Apesar da noção da criação de um heterocosmo, ainda se concebia um mundo real que seria refletido no espelho mimético da literatura.

Professora de Literaturas de Língua Inglesa da Ufal; doutoranda em Teoria Literária pela Universidade Federal de Pernambuco.

1 Ver The Norton Anthology of English Literature, vol. 1, $5^{\text {th }}$ edition, p.504-25. 
Desde a exaltação romântica da originalidade e do gênio do poeta/ autor, cuja mente nào só refletia, mas transformava o mundo em seu redor, passando pela pretensào realista de registrar o mundo e as relaçòes humanas tal como se apresentam na realidade, chegamos ao dilema epistemológico modernista, como coloca Dick Higgins, citado por Brian McHale, "Como posso interpretar esse mundo do qual faço parte? E quem sou eu nele?" (McHale, 9). ' Outras interrogaçòes levantadas pelo modernismo sào: "O que existe para ser conhecido?"; "Quem pode conhecê-lo?" "De que forma podemos conhecê-lo, e com que grau de certeza?" (...) "Como o objeto do conhecimento se transforma à medida que passa de conhecedor/a para conhecedor/a?"; "Quais os limites do que podemos conhecer?" (id.ibid). Mesmo inaugurando uma relaçào mais conflituosa com as possibilidades de se apreender e representar o real, o modernismo ainda acreditava na existência do referente - de um real passível de ser representado, muito embora ele exigisse novas formas e novas estratégias de representaçào.

Quando chegamos ao que chamamos hoje de ficçào pós-moderna, observamos que os questionamentos vão além dos limites epistemológicos da representaçào, diante da impossibilidade de se apreender o real. A arte pós-moderna, como coloca Fredric Jameson, nào vislumbra um fim para o processo de mudança; daí seu interesse em rupturas, em eventos (um momento jamais é igual ao outro); em variaçòes em vez de fixidez. A ficção pós-moderna nào trabalha mais com uma linguagem transparente, mimética, que reflete o real; a "realidade" já foi em si encapsulada por imagens culturais que ocuparam o lugar da "natureza" - um fenômeno que Jameson chama de "aculturaçào do real". Portanto, com a dissolução do referente, a interrogação dominante da ficçào pós-moderna, como aponta Mc Hale, é ontológica: "Que mundo é esse?" "O que pode ser feito nele?" "Quais dos meus 'eus' pode fazê-lo?". Ainda segundo McHale, outras questòes características do pós-modernismo residem tanto na ontologia do texto literário em si como na ontologia do mundo que ele projeta: "O que é um mundo?"; "Que tipos de mundo existem, como sào constituídos, e como diferem entre si?"; "O que acontece quando diferentes tipos de mundo sào confrontados, ou quando os limites entre mundos sào violados?"; "Qual o modo de existência de um texto, e qual o modo de existência do mundo (ou mundos) que ele projeta?"; "Como é estruturado um mundo projetado?" (10).

Tỉdas as traduçess são de minha intera responsabilidade, c foram feitas com o fim exclusion de citaçios neste ensaies. 
Na carência de um mundo palpável e de uma linguagem que possa lhe servir de espelho, a ficçào pós-moderna se vale dessa instabilidade ontológica e do caráter irrecuperável da experiència vivida para descrever outros mundos, outros universos que nào aquele(s) no qual acreditamos que vivemos. Isso nào implica necessariamente, como aponta McHale, uma tentativa de encontrar bases explicativas para o nosso mundo, mas além, obviamente, do próprio heterocosmo que é a ficçào em si, implica a invençào nào só de universos possíveis e inteligiveis, como também de universos impossiveis e ininteligíveis.

Por que nào dizer que a ficçào pós-moderna tenta explorar discursivamente os impasses epistemológicos do modernismo, muitas vezes, articulando a própria impossibilidade de um sujeito-autor/a-leitor/a detentor/ a de um ponto de vista fixo e coerente?

The.Ponerbook:3 (2000), da inglesa, Jeanette Winterson, desloca tanto a figura autoral quanto a do/a leitor/a dos lugares pré-definidos de criador/a e de intérprete. Ao multiplicar as vozes da/o suposto/a autor/a das várias micronarrativas que compòem o livro, torna mais complexa ainda a funçào nào só do/a leitor/a-personagem como a do/a leitor/a real, que passa a ocupar uma série de posiçòes subjetivas provisórias e instáveis.

\section{IN'TERAÇÃO NO CIBERESPAÇO: CIBERAUTOR/A E CIBERLEITOR/A}

Ao abrirmos o livro, antes mesmo da folha de rosto e informaçòes sobre a autora, Jeanette Winterson, deparamo-nos de imediato com um towerbok aberto ${ }^{4}$, exibindo na tela a frase que norteia as estórias, "Freedom for just one night". Em vez de um índice propriamente, temos um "menu", em que os segmentos narrativos ora recebem títulos relativos à temática explorada, ora sào identificados por toda uma terminologia de comandos operativos e interativos de um computador, a sua maioria em letras maiúsculas: "OPEN HARD DRIVE", "NEW DOCUMENT", "SEARCH", "VIEW", "VIEW AS ICON", "EMPTY TRASH", "SPECIAL", "HELP", "SHOW BALLOONS", "CHOOSER", "QUIT", "REALLY QUIT", "RESTART”, "SAVE".

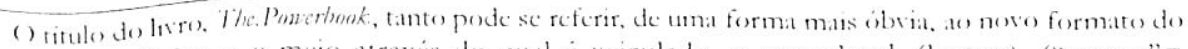
livero detrinice c o meio atravis do yual i veiculado, " powerbonk (laptop). ("power" =

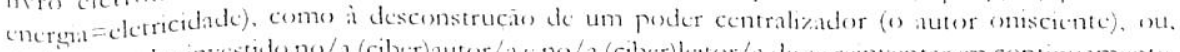
anda, a poder investidono/a (ciber)autor/a e no/a (ciber)lentor/a de se rensentarem continuamente, a) longer das narrativas.

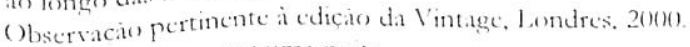

laberdade por apenats uma note. 
The.Poverbook, na verdade, encena narrativas produzidas no ciberespaço-essa espécie de "hiperterminal planetário onde toda informaçào circula" (Nicola, 156) —e que nascem a partir de uma relação virtual entre autor/a e leitor/a.

No início, temos a impressão de que o foco narrativo está centrado em Ali, um/a escritor/a que conta estórias por encomenda, e que se autodenomina um/a estilista da linguagem -"a language costumier". Na verdade, Ali estiliza não só a linguagem, mas através dela, as identidades de seus/suas clientes e a sua própria. Em nenhum momento, coloca-se como sujeito criador, onisciente, imbuído de poder pela manipulação da linguagem. Numa perspectiva bem foucaultiana, Ali é tào produto de suas narrativas, como as pessoas que o/a procuram, buscando a liberdade por uma noite—a liberdade de se transformarem em outras pessoas. Uma transformaçào que se dá no ciberespaço, sem contato físico ou visual:

Noite. As ferramentas de busca estão paradas.

Continuo lançando estórias, como uma mensagem numa garrafa, com a esperança de que você as leia, e me responda. Você não responde.

Avisei-lhe que a estória poderia se transformar nas minhas mãos. Esqueci que o/a contador/a de estórias se transforma também. Eu estava nas suas mãos. (83)

O livro que se materializa em nossas màos, leitores/as reais, parece, muito mais, uma transcrição da interação entre Ali e seus/suas clientes e do processo de construção das diversas micronarrativas, as quais, vale lembrar, podem ser interrompidas, sofrer alteraçōes, ou ser até completamente eliminadas, se não agradarem a/o cliente/leitor/a/personagem, quase que nos moldes de um hipertexto construtivo " e/ou de uma hiperficção. ${ }^{7} \mathrm{O} / \mathrm{a}$

Com respeto a suposta liberdade do/a leitor/a interativo/a, e importante lembrarmo-nes de yue a rede também apresenta limitaçoes, yue, por sua $12 \%$ lımitam e delimitam, mesme em um espaçe rastissimo como a Internet, as possivecis escolhas desse/a leitor/a. Assim, Michacl foyce distungue entre dos tipos de hipertexto, o exploralörio, que exige da audiéncia a capacidade de organizar de forma cocrente e sistemática as informaçós obtidas na rede; co construtinn, yue exige do/a leitor/a "capacidade de açāo", para "criar, modificar e recuperar encontros particulares no contexte de um sistema de conhecimentos em expansäo" (Joyce, 1995, in Bcllci, $\Gamma .76$ ).

A hiperficçase, no meio eletronico de fato, caracteriza-se pela abertura yue oferece ao/a leitor/a de entrar e circular no texto por diversas portas e de diversas formas, trilhando uma infinidade de enredos possivess. Torna-se impossivel reduzir uma hiperficçāo a um enredo básico dentre os víress possivecis. (ver Bellei, 115). Aqui sugiro que Winterson apenas simula a construçäo constante de uma hiperficçàs. $\mathrm{s} \mathrm{cm}$ começo, meio ou fim, em que o/a autor/a, mais do que nunca, cscreve em funça de, c cm conjunção com, o/a lcitor/a. 
leitor/a-personagem passa a ter o poder de interferir no desenrolar de "sua" história, e, dessa forma, Winterson confunde, minimiza e desestabiliza a relaçào tradicionalmente hierárquica entre autor/a e leitor/a.

Ao final de uma das histórias, Ali, o/a escritor/a sem corpo-o próprio simulacro da funçào do autor, para usar o termo de Foucault-que se materializa apenas através de suas palavras na tela do computador, recebe uma mensagem de um/a cliente insatisfeito/a com o rumo de "sua" narrativa. Ao que Ali rebate alegando que, uma vez que começa uma história, esta pode seguir caminhos imprevisíveis (26), negando mais uma vez a figura do autordemiurgo, que julga ter pleno controle sobre a sua criação. A partir daí se segue um diálogo inusitado entre "escritor/a-personagem" e "leitor/apersonagem", em que trocam críticas, sugestões e novas idéias para uma nova narrativa. Entretanto, mesmo esse contato, que, supostamente, ocorre em um intervalo entre uma estória e outra, está totalmente imbricado no universo virtual e ficcional, e não há mais como definir ou identificar uma realidade original; assim como também nào existe um centro, muito menos um sujeito unitário que possa ser representado na sua unicidade e totalidade:

Você disse, Quem é você?"

"Me chame de Ali".

"Esse é seu nome verdadeiro?"

"Verdadeiro o suficiente".

"Homem ou mulher?"

"Importa?"

"É uma coordenada."

"Esse é um mundo virtual."

"OK, OK-mas só pra constar-homem ou mulher?"

"Pergunte à Princesa."

"Aquilo era apenas uma história."

"Isso é apenas uma história."

"Que eu chamo de uma história verdadeira."

"Como você pode saber?"

"Eu sei, porque faço parte dela."

"Estamos juntos/as nela agora."

Houve uma pausa—então digitei, "vamos começar. Que cor de cabelo você quer?"

"Vermelho. Sempre quis cabelos vermelhos."

(...)

"O que devo vestir?"

"Você escolhe. Combat ou Prada?" 
"Quanto posso gastar em roupas?"

"Que tal \$1000?"

"Todo o guarda-roupa ou só uma roupa?"

"Você está preso/a a um orçamento?"

"Você é o/a escritor/a."

"É a sua história." a autor/a:

E, por fim, o golpe final na instituiçào clássico-romântico-realista do/

"O que aconteceu com o/a autor/a onisciente?"

"Virou interativo/a". (26-7)

Interessante observar como o/a leitor/a, habituado/a ao modelo de leitura convencional, ainda se prende a determinados conceitos tão arraigados como o de autor onisciente e resiste a entrar no jogo da interatividade. Aceito o jogo, toda e qualquer relação estável entre autor/a e leitor/a é subvertida e ambos/as sào autorizados/as e desautorizados/as ao longo do processo. Winterson cria, assim, um universo hipertextual em que o/a leitor/a tem toda a liberdade de se inventar e se re-inventar infinitamente. A exemplo de vários escritores de vanguarda como Sterne, W. Faulkner, James Joyce, Borges, Calvino, Winterson instaura uma nova modalidade textual dentro do tradicional texto impresso; transforma seu/sua leitor/a personagem em leitor/a interativo/a -o que chamaria de ciberleitor/a-na medida que este/a é interpelado/a diretamente pelo/a autor/a e convidado/a a tomar parte ativa no processo narrativo, autorizando inclusòes e exclusòes, e efetuando toda sorte de escolhas.

Na teoria da informática, interatividade é "a comunicação recíproca entre o usuário [sic] de um sistema de computadores e a máquina, por intermédio de um terminal dotado de um monitor de vídeo". ${ }^{8}$ Inseridos/as nesse sistema de relaçòes informáticas, autor/a e leitor/a constituem-se não apenas enquanto terminais virtuais, invisíveis, como também enquanto indivíduos cujas identidades são produzidas a partir de estímulos mútuos dentro desse novo modo de comunicação. ${ }^{9}$ Poderíamos até dizer que a interação que se dá entre autor/a e leitor/a trata-se tanto de uma relaçào interpessoal, vis to que há troca de informações, como também de uma reinvençào dessa interpessoalidade, já que essas "pessoas" nào correspondem a indivíduos

Grande Lincilopedia I arouse Cultural, vol.6, p. 3.251, in Nicola, 28.

Ver l.éry, (iberistlura, p. 36, in Nicola, 29. 
"reais" fora do ciberespaço. Circulam, entào, em uma rede, cujas intersecçòes estào em contínua expansão, em um espaço semelhante ao que Baudrillard chama de hiperreal, onde nào existem coordenadas definidas, e o sujeito se perde num movimento incessante através de uma infinidade de canais e "links". O sujeito já não possui mais uma única direçào a escolher, segue um movimento espiralado, cada vez mais divorciado de um remoto referente. E assim, a relaçào entre autor/a e de leitor/a é problematizada, gerando uma espécie de angús tia da incerteza, e seus papéis tornam-se permeáveis e intercambiáveis; o autor/ a é tào leitor/a quanto o / a leitor/a é autor/a:

Noite.

Estou sentada/o diante da tela lendo essa estória. Por sua vez, a estória me lê.

Escrevi essa estória, ou foi você, escrevendo através de mim, da mesma maneira que o sol acende o fogo através de um pedaço de vidro? (209)

Numa entrevista, a própria Winterson defende que nào podemos mais continuar escrevendo uma ficçào oitocentista tradicional; é inegável que o Modernismo e o Pós-Modernismo mudaram o mapa, e que qualquer escritor/ a de peso vai querer desenhar novos caminhos nesse mapa. Nas suas próprias palavras: "Não quero ser curadora de um Museu da Literatura; quero ser parte do futuro"."

\section{CORPOS, HISTÓRIAS, IDENTIDADES}

As histórias de Ali - cujo gênero permanece indefinido - nào apenas criam narrativas em que as pessoas podem se imaginar em um universo novo; na verdade, estas elaboram mitos de origem alternativos de identidades cyborg, num espaço onde corpos e histórias se formam e se re-formam mutuamente, e onde a linguagem não é um determinante que limita as possibilidades de configuraçào desses corpos. Circulando nos circuitos de um computador, os corpos sào as próprias histórias, e ambos estào em constante mudança, ocupando identidades multi-situadas, entrelaçadas numa rede de possibilidades múltiplas e provisórias, jamais esgotadas, como num jogo de combinaçòes infinitas entre cadeias de DNA, ou como o movimento de regressào infinita entre cadeias de significados acessados através de

"I Intrevista publicada cm um volume da séric l intage lating TeN\%, yue apresenta e discute os temas, gêneros e técnicas narrativas utilizadas por feanette Winterson em alguns de scus romances. 
hiperlinks. Como o/a próprio/a Ali "avisa" a seus/suas clientes no inicio, "as pessoas chegam como elas mesmas e saem como outras" (3). A promessa de Ali a quem lhe procura não é nada menos que a "liberdade por uma noite. Por apenas uma noite a liberdade de ser uma outra pessoa"(4). O desejo é o de transformação. Transformação que se efetua na conjunção entre corpo, linguagem, tecnologia e narrativa.

As narrativas de Ali são protéicas e fugazes como a própria realidade que tenta transformar. Na verdade, nào diferencia o real da ficção. Afinal tudo são histórias, inclusive a nossa própria vida: "história da criação, história de amor, de horror, de crime, a estranha história sobre mim e você" (4). As narrativas transformadoras de Ali são extensões ou expansões (distensòes?) dessa grande narrativa que vivemos no mundo "palpável". É impossível conhecer o real; teoricamente, pode ser impossível conhecer um corpo fora das marcas simbólicas que fazem sua existência viável, mas no campo ficcional é possível "desmarcá-lo", dar-lhe formas outras, que penetram além da regiào dos disfarces que nos fazem inteligíveis.

Ali nào se propòe a criar mundos similares ao que vivemos. Logo no início, avisa que se trata de um mundo inventado-mundos que podem se descortinar a partir de mínimos incidentes (32). Remetendo-nos ao que Gaggi fala sobre o hipertexto, como "uma estrutura narrativa que se move de um incidente a outro, de um grupo de personagens a outro, com pouco sentido de uma organização geral" (99). De fato, as narrativas de Ali (se é que podemos realmente atribuí-las a ela/e) se deslocam no tempo e no espaço, obedecendo a uma lógica própria, e, aparentemente, casual e acidental: "Mais tarde, muito mais tarde, aparece uma passagem aérea na tela-destino: Nápoles. Talvez você queira uma ópera, não uma estória" (83). Sem um roteiro ou planejamento prévio, as histórias podem tomar forma a partir de estímulos gerados no próprio ciberespaço, a passagem-motivo aparece na tela sem ter sido solicitada, semelhantemente às janelas "pop-ups" que inundam nossas telas de computador com propagandas.

As narrativas trabalham, também, com a precariedade da linguagem em apreender realidades e existências que circulam fora do discurso, e com a fragilidade da linguagem também em projetar/idealizar/determinar a forma material que impõe limites aos nossos corpos. Os corpos, na verdade, são vistos como mais uma ilusão de verdade, de certeza, e de fronteiras fixas. Ilusão que precisa ser desconstruída para que haja histórias, para que haja transformação. Assim, Ali pede que se dispam, não só de suas roupas, como 
de seus corpos, uma vez que estes são meros disfarces--ficçòes de uma estabilidade identitária, que se dá na e pela linguagem. E eis que nos deparamos com um paradoxo e um impasse. Como através da própria linguagem, podemos falar de um corpo antes mesmo deste ser marcado pelo simbólico? O que resta de nossas identidades se nos desvestirmos do corpo, e, por conseguinte, das marcas culturais que nos tornam humanos/as e inteligíveis? ${ }^{11}$

Acredito que, em The.Powerbook, Winterson se propõe a explorar no hiperespaço-um espaço deslocado, desconexo e incoerente, onde o indivíduo se fragmenta em identidades múltiplas e descontínuas - a própria lógica do simulacro, em que, na ausência do referente, resta-nos nada além de representações de representações, como numa cadeia infinita de espelhos, cada vez mais dissociada do "real". Ali, que é apenas um referencial deslocado e distante, de fato, não se imobiliza diante da grande impossibilidade que seria falar de sujeitos que estão fora do discurso.

As (im)possibilidades exploradas por Ali são todas aquelas que foram apagadas, marginalizadas, postas no limbo pela força da repetiçào compulsória de normas restritivas - pela força da proibição-mas que irrompem pelos interstícios dos discursos da cultura como potenciais a serem articulados discursivamente.

Supostamente, desvestidas de quaisquer marcas culturais, as personagens de Winterson mergulham num universo virtual, que rearticula, reconta e revisa histórias culturalmente cristalizadas em um movimento contínuo de desnudamento das incertezas, que, de fato, constituem a nossa "realidade" e as nossas identidades. A partir de imagens de fragmentação e de

\footnotetext{
"Levantar essas questões implica pensar a relação entre a linguagem e a forma como ela estabelece a materialidade do corpo. Se afirmarmos que a lingungem produz o corpo, atribuindo a ele significados que se tornam a sua identidade "natural", pareceria inviável, então, pensar ou tentar recuperar o corpo fora da linguagem. Entretanto, o corpo, enquanto referente, constantemente recusa-se a ser contido por um significado. Assim, como nos lembra Butler, a impossibilidade da linguagem em capturar esse referente-o corpo-leva-a a tentar indefinidamente, e em vão, essa captura, essa "circunscrição". Contudo, ao colocarmos o corpo fora da linguagem, já o fazemos em termos da própria linguagem. Melhor dizendo, a linguagem c a materialidade estão completamente imbricadas uma na outra; dentro dessa lógica, o referente nào existe aparte do significado, o que não quer dizer, entretanto, que seja reduzido a ele. Nas palavras de Butler, "sempre já implicadas uma na outra, sempre já excedendo uma à outra, a linguagem e a materialidade jamais são totalmente idênticas nem totalmente diferentes". (Bodies that Matter, p.69). Ao devestir o corpo das marcas culturais, Winterson, de fato, explora outros termos em que o corpo pode ser escrito dentro da própria linguagem que tradicionalmente o contém e o aprisiona. Reafirmando o corpo como um referente resistente e irredutivel a um único significado, Winterson abre, assim, um espaço discursivo para reconsiderar e renegociar as silenciosas relações político-ideológicas que constituem e determinam a anatomia do corpo e seu imaginário pessoal e social.
} 
reconstituição do corpo, Winterson inventa um espaço atemporal em que identidades e corpos circulam em movimentos ex-cêntricos, sem referencial definido, e que não se reduzem a uma sexualidade única e fixa.

Em uma das histórias, que é narrada na primeira pessoa, a narradora nos conta que nasceu mulher, mas a mãe a travestia de homem, para ver se assim ela conseguiria trazer riquezas para o lar. Um filho homem seria uma bençào; uma mulher, um desperdício. Assim, sua mãe executa um enxerto "horticultural", transformando uma tulipa embalsamada em um pênis para a sua filha. Dessa forma, através da criação de um universo simbólico que ironiza ao extremo os modelos normativos aos quais estamos sujeitadas/os, Winterson traz à tona a fragilidade e a artificialidade desses mesmos modelos corporais. Uma tulipa pode ser um pênis e com o tempo de fato se tornar funcional:

(...) Então algo estranho começou a acontecer. Enquanto a princesa beijava e acariciava minha tulipa, minhas próprias sensações intensificaram-se, ainda assim não mais que o meu espanto, à medida em que sentia meu disfarce tomar vida. A tulipa começou a ficar ereta. (The. Powerbook, p. 22)

O que me faz lembrar o mito do cyborg, criado por Donna Haraway, em "A Manifesto for Cyborgs", para dar conta, no âmbito da teoria política e social, de identidades limítrofes, canibalizadas por um insidioso sistema de informações, que ela chama de "informática da dominação". Dentro desse sistema, objetos, espaços e corpos se intercruzam, e as dicotomias ente mente e corpo, animal e humano, organismo e máquina, público e privado, natureza e cultura, homem e mulher, primitivo e civilizado são ideologicamente questionadas e passam a se dissolver. Para Haraway, o cyborg se constitui numa identidade pós-moderna, ao mesmo tempo pessoal e coletiva, constantemente montada e desmontada:

Um cyborg é um organismo cibernético, um híbrido de máquina e organismo, uma criatura da realidade social assim como uma criatura da ficção. A realidade social são as relações sociais vividas, nossa construção política mais importante, uma ficção capaz de mudar o mundo. (191)

Em um mundo pós-gênero, sem hierarquias, as marcas sexuais dos corpos são apagadas e qualquer mito baseado na totalidade é substituído pelo gozo da multiplicidade. Haraway descreve o mundo cyborg dentro de uma 
perspectiva que elimina fronteiras fixas. O mundo cyborg, como ela mesma coloca, consiste em "realidades sociais e corporais vividas, nas quais as pessoas nào têm medo de seus parentescos com animais e máquinas, não têm medo de identidades permanentemente parciais nem de pontos de vista contraditórios" (196).

Winterson, no âmbito da ficção, subverte os mitos de origem, e inventa seus próprios personagens cyborg, que nascem, ganham vida, e se transformam no circuito eletrônico-cibernético dos microcomputadores, na linguagem que lhes apreende de forma precária, e nas camuflagens e disfarces que os fazem se confundir com o mundo natural, animal e tecnológico. As tulipas, distintivamente diferentes nas suas semelhanças, assemelham-se, assim, a nós humanos (ver The.Powerbook, p.3).

O corpo, misto de mulher, tulipa e homem, está disfarçado ou é ele mesmo um disfarce? É essa a instigante questão que Winterson nos coloca: "Mas e se meu corpo for o disfarce? E se pele, osso, fígado, veias forem as coisas que uso para me esconder? Eu os vesti e não posso mais tirá-los. Isso me aprisiona ou me liberta?" (15). E voltamos ao nosso antigo impasse: se pensamos o corpo como um disfarce descartável que podemos sempre renovar-e é essa a proposta de Ali-será que podemos dizer que Winterson tenta recuperar o corpo anterior à linguagem, anterior às marcas simbólicas que o tornam humanamente possível? Ou será que ela dramatiza um jogo irônico com aquelas possibilidades de configuração do corpo sexuado reprimidas pela lei? ${ }^{12}$

Acredito que a linguagem de Winterson busca exceder a própria linguagem, ao pensar corpos que se constituem contra os parâmetros do simbólico e dos modelos heterossexistas que definem o que se qualifica como "sexo". Imaginar o corpo como um disfarce significa expor a contingencialidade e a fragilidade da própria linguagem que o forma e o faz inteligivel; significa explorar o ininteligível, o "inumano", numa tentativa de desestabilizar um processo de materialização de corpos e identidades limitadas e fixas. Winterson subverte os espaços, os focos e a linguagem narrativa, e, assim, subverte a teleologia da lei, criando corpos e partes de corpos fora do centro, e que não se sustentam dentro dos padrões culturais de inteligibilidade.

$12 \mathrm{Em}$ A História da Sexualidade vol.1, Foucault discute como a lei reguladora, que busca limitar ou proibir certas práticas e sujeitos, no seu próprio processo de criação e de imposição dessas proibições, abre espaços discursivos para a resistência e para a sua própria rearticulação, ressignificação e subversão. 
Paralelamente, desenvolve uma grande metáfora do caráter elusivo e fantasmático do sujeito, que escapa à linguagem, ao mesmo tempo em que só se constitui, mesmo que provisoriamente, através dela. Assim, desconstrói, sobretudo, o conceito do/a autor onisciente e do/a leitor/a capaz de decodificar as estruturas narrativas e semânticas do texto, uma vez em que ambos se configuram como construçòes instáveis do próprio discurso, que jamais pode recuperar as suas presenças anteriores a ele próprio. Como a firma Derrida, "jamais houve um sujeito antes deste ser nomeado e inscrito e dividido" pela linguagem (apud Gaggi, p. 47).

\section{O FIM, O (RE)COMEÇO}

Dessa forma, The.Poverbook desafia os limites da linguagem e dilui a figura do autor/a em uma infinidade de pontos de vista, que se deslocam no tempo e no espaço, através de narrativas que se constroem e desconstroem, recorrendo a citações, paródias, contos de fadas, mitos contemporâneos, e distanciando cada vez mais a figura do/a autor/a da figura de um/a criador/ a de uma obra original, e, conseqüentemente, problematizando ao extremo as possibilidades do/a leitor/a de encontrar coerência, pelo menos, tal como se entendia na ficçào de cunho mais realista, numa estrutura intencionalmente dispersa e desconexa.

Sobre as inovações estruturais em The.Powerbook. Winterson diz que Tem havido muita conversa sobre a morte do livro ${ }^{13}$, mas não existe tal coisa; apenas uma transformação do livro, tanto como um artefato quanto como uma idéia. Em um novo século, precisamos de novas formas de olhar coisas familiares-é a única maneira de torná-las nossas, do contrário, são apenas emprestadas e logo se tornam clichês. (...) A forma do livro [The.Powerbook], sua estrutura, sua linguagem, é uma forma diferente de trabalhar. ${ }^{\text {it }}$

Na verdade, o que The.Powerbook nos traz é um protótipo ainda impresso, por assim dizer, de escrituras cibernéticas que, em vez de divergirem de, ou convergirem a, um sujeito-leitor, situado em um ponto determinado e

"Para uma discussão mais aprofundada sobre as respostas divergentes às novas tecnologias textuais, dayucles que temem o fim do livro e daqueles que louvam o fim da "tirania da linha", supostamente proporcionado pelo hipertexto, ver Bellei, 20(12, p. (1)-42.

it Reynolds, Margaret \& Jonathan Noakes, eds. Vintuge Liring Texts: feanelte Winterson. Jondon: Vintage, 2003. 
fixo no tempo e no espaço, dispersam-se em uma textualidade expandida, e recriam a própria noção de autor/a. $\mathrm{A} / \mathrm{s}$ origen/s do texto se tornam cada vez menos relevantes e, no espaço da textualidade eletrônica, mesmo aqui apenas simulada, passamos a ter a figura do/a ciberautor/a e do/a ciberleitor/ a-sujeitos e corpos pós-modernos, que, tal qual o cyborg de Haraway, configuram um sistema humano-cibernético, que se relaciona com o mundo e se reconhece enquanto sujeito apenas na complexa tecnologia hipertextual. São subjetividades e identidades que se formam e se transformam em um fluxo intenso e contínuo de idéias e imagens, que nào buscam representar absolutamente nada em particular, e escapam a qualquer critério de verossimilhança, visto que no universo hiperreal em que circulam, nada é igual ou similar a nada, a não ser às suas próprias criações. ${ }^{15}$

Podemos dizer que ao incorporar modalidades narrativas hipertextuais ao espaço tradicional do livro impresso, ao encenar o jogo de construção de narrativas entre ciberautor/a e ciberleitor/a, Winterson oferece a nós, leitores/ as reais, uma nova forma de experienciar o bom e velho livro, fazendo-nos "navegar" por entre as páginas, assumindo a perspectiva do/a ciberleitor/a. A escrita convencional se faz passar por escrita eletrônica e traz para a mídia impressa uma nova forma de textualidade que exige, igualmente, uma forma totalmente nova de ler, e modifica radicalmente, assim, o que, em geral, se entende por autor e leitor.

Em The.Powerbook, o texto, mais do que nunca, é rede, tecido, trama, que se expande continuamente, no nosso imaginário, mesmo após fecharmos a última página. Dessa forma, Winterson revitaliza o modelo de leitura tradicional, introspectivo, temporal e linear, acentuando a interatividade entre autor/a e leitor/a, através de uma narrativa aberta, descentrada e nào-linear, $\mathrm{e}$ transformando-nos em ciberleitores/as de um texto ficcional impresso.

\section{REFERÊNCIAS}

BELLEI, Sérgio L.P. O livro, a literatura e o computador. Florianópolis: Edufsc, 2002.

BUTLER, Judith. Bodies that matter: on the discursive limits of "sex". New York: Routledge, 1993.

is Ver Gaggi, p.59. 
FOUCAULT, Michel. História da sexualidade: a vontade de saber. Tradução Maria Thereza da Costa Albuquerque e J. A. Guilhon Albuquerque. Rio de Janeiro: Graal, 1993.

GAGGI, Silvio. From text to bypertext: decentering the subject in fiction, film, the visual arts, and electronic media. Philadelphia: University of Pennsylvania Press, 1998.

HARAWAY, Donna. A manifesto for cyborgs: science, technology, and socialist feminism. In: NICHOLSON, Linda (ed.). Feminism/postmodernism. New York: Routledge, 1990. p. 190-233.

McHALE, Brian. PostModernist fiction. New York: Routledge, 1987.

NICOLA, Ricardo. Cibersociedade: quem é você no mundo on-line? São Paulo: SENAC, 2003.

REYNOLDS, Margaret and Jonathan Noakes. Vintage living texts: Jeanette Winterson. London: Vintage, 2003.

WINTERSON, Jeanette. The.PowerBook. London: Vintage, 2000.

www.jeanettewinterson.com (Site oficial). 